\title{
IMIQUIMOD COMO TRATAMIENTO DE LA MICOSIS FUNGOIDE PALPEBRAL
}

\section{IMIQUIMOD IN TREATMENT OF PALPEBRAL MYCOSIS FUNGOIDES}

\author{
SOLER-MACHÍN J ${ }^{1}$, GILABERTE-CALZADA Y ${ }^{2}$, VERA-ÁLVAREZ J ${ }^{3}$, \\ COSCOJUELA-SANTALIESTRA $\mathrm{C}^{2}$, MARTÍNEZ-MORALES J ${ }^{1}$, OSÁN-TELLO M ${ }^{4}$
}

\begin{abstract}
RESUMEN
Caso clínico: Presentamos el caso de un varón de 37 años de edad que presentaba una micosis fungoide, el más frecuente de los linfomas T cutáneos, con localización exclusivamente palpebral que había sido tratado previamente con corticoides tópicos. Se instauró un tratamiento con Imiquimod al $5 \%$ en crema tres veces semanales.

Discusión: Con el uso de este medicamento, se consiguió una gran mejoría clínica del paciente, por lo que consideramos muy importante tener en cuenta este inmunomodulador para el tratamiento de esta enfermedad, de importancia por su capacidad de leucemización.
\end{abstract}

Palabras clave: Micosis fungoide, Imiqimod, Linfoma T cutáneo.

\begin{abstract}
Clinical case: Our patient was a 37-year-old male with palpebral mycosis fungoides, the most common T-cell cutaneous lymphoma. He had been treated previously with topical corticosteroids. We treated him with Imiquimod cream (5\%) three times a week.

Discussion: A clinical improvement was obtained with this drug, so we believe immuno-modulating agents need to be considered in the treatment of palpebral mycosis fungoides, especially because of its capacity of being a reflection of leukaemia (Arch Soc Esp Oftalmol 2006; 81: 221-224).
\end{abstract}

Key words: Mycosis fungoides, Imiquimod, T-cell lymphomas.

Recibido: 22/4/05. Aceptado: 19/4/06

Servicio de Oftalmología. Hospital General San Jorge. Huesca. España.

1 Licenciado en Medicina. Adjunto/FEA.

2 Doctora en Medicina. Adjunto/FEA. Servicio de Dermatología.

3 Doctor en Medicina. Adjunto/FEA. Servicio de Anatomía Patológica.

4 Licenciado en Medicina. Jefe de Servicio.

Correspondencia:

Javier Soler Machín

$\mathrm{C} /$. Alcañiz, $3,2 .^{\circ} \mathrm{D}$

22004 Huesca

España

E-mail: javiersolermachin@hotmail.com 


\section{INTRODUCCIÓN}

Los linfomas cutáneos de células T son los procesos linfoproliferativos cutáneos más frecuentes (1). Son trastornos malignos, sin extensión extracutánea al diagnosticarlos, que presentan proliferación clonal de células T. El más frecuente es la micosis fungoide, cuya incidencia es 0,5-1/100.000 habitantes (1).

La micosis fungoide se caracteriza por aparición sucesiva de máculas eritematosas, placas sobreelevadas y tumoraciones. Cuando se leucemiza, se denomina síndrome de Sezary. Existen varios tipos, como la micosis fungoide folicular, en cabeza y cuello y con lesiones acneiformes foliculares, alopecia y prurito (2); o la reticulosis pagetoide, en extremidades. La localización exclusiva palpebral es excepcional.

Se presenta un caso de micosis fungoide palpebral que respondió al tratamiento con Imiquimod.

\section{CASO CLÍNICO}

Varón de 37 años, sin antecedentes, que acudió a la consulta con una lesión en el canto medial del párpado superior izquierdo, no pruriginosa, de cuatro meses de evolución. Había sido tratado con corticoides tópicos. Al explorarlo presentaba una placa eritematosa, brillante, con quistes de millium, de un tamaño de 1,7 cm de diámetro (fig. 1). No existían otras alteraciones.

El diagnóstico diferencial se planteó entre eczema, micosis fungoide o millium en placa (3). Se realizó una biopsia cutánea que informó de la existencia de infiltrado inflamatorio en la dermis papilar constituido por linfocitos de pequeño y mediano tamaño, entremezclados con células histiocitarias y eosinófilos. El infiltrado inflamatorio a veces contactaba con la capa basal epidérmica, que no mostraba signos de alteración, excepto focos aislados de vacuolización y ocasional exocitosis linfocitaria (fig. 2). Las técnicas de inmunoperoxidasa demostraron que las células linfocitarias proliferantes eran predominantemente de tipo T (UCHL-1 y CD-3 positivas) atípicas, confirmándose el diagnóstico de linfoma $\mathrm{T}$ cutáneo tipo micosis fungoide.

Las pruebas complementarias; bioquímica, hemograma, sedimento urinario y estudio de extensión fueron normales. Se instauró tratamiento con Deflazacort $30 \mathrm{mg}$ en pauta descendente un mes. En

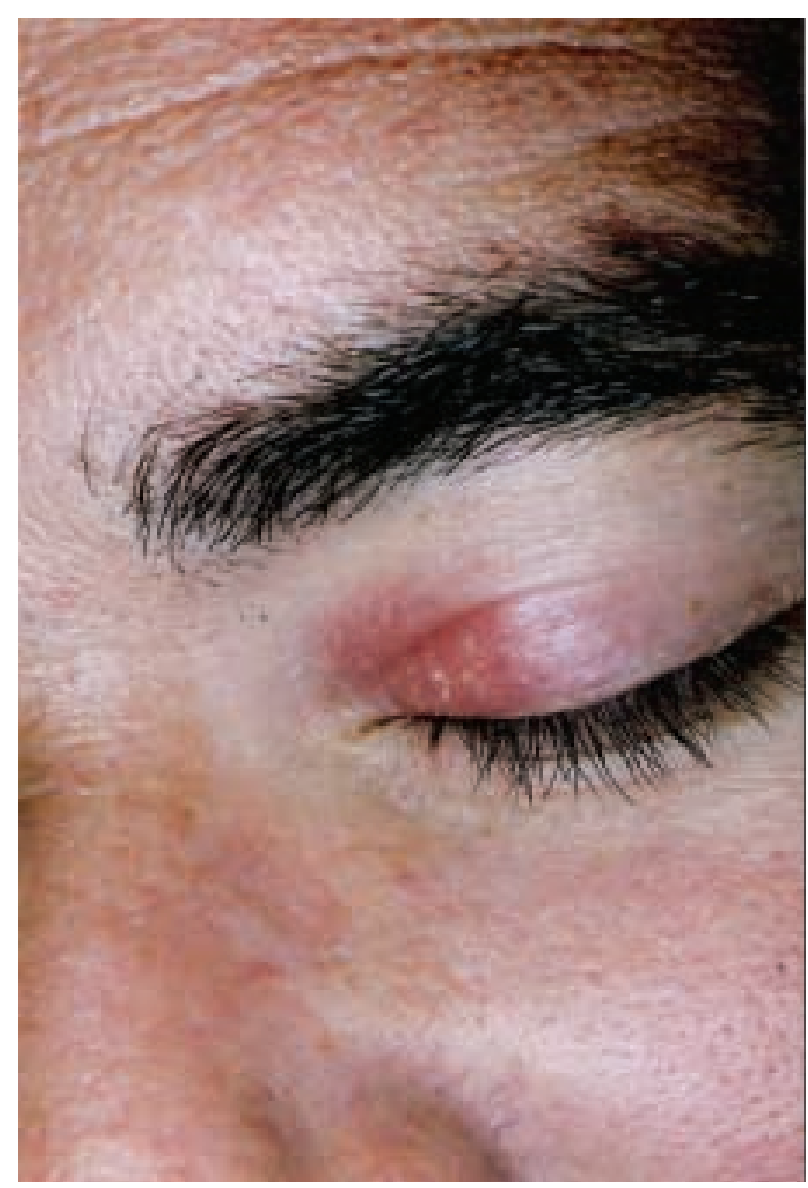

Fig. 1: Placa eritematosa con algún quiste de millium en párpado superior izquierdo.

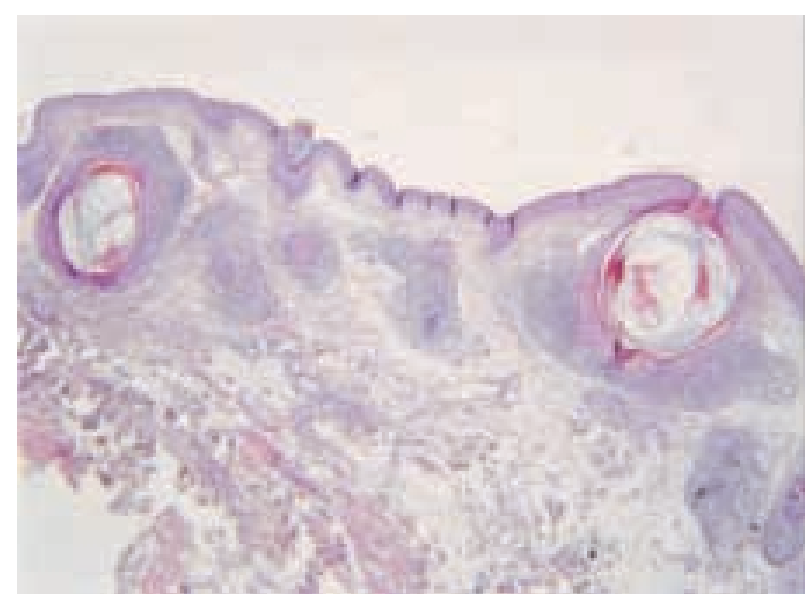

Fig. 2: Piel de párpado con un infiltrado linfocitario dispuesto preferentemente alrededor dealgunos folículos pilosos quistificados en forma de millium (H-E, 10x). 
la siguiente revisión la placa eritematosa había aumentado alcanzando $2 \mathrm{~cm}$ de diámetro, y habían aparecido más quistes de millium; existía una nueva lesión en párpado superior derecho. Se retiró el corticoide oral y se inició tratamiento con Imiqimod al $5 \%$ en crema, tres aplicaciones semanales. Se administró colirio de Diclofenaco para evitar la conjuntivitis que podría producir el Imiquimod.

A los dos meses de tratamiento se evidenció una mejoría de la zona palpebral inflamada y la disminución del número de quistes de millium; a los tres meses sólo se encontraron tres quistes, sin reacción inflamatoria palpebral.

A los cinco meses se extirparon las lesiones residuales cutáneas. El informe anatomopatológico reveló un infiltrado inflamatorio linfocitario alrededor de algunos folículos pilosos quistificados en forma de millium. En el epitelio se apareció una exocitosis con pequeños grupos de linfocitos, sin evidenciarse microabscesos de Poitrier. Con técnicas de inmunoperoxidasa se vio que el infiltrado era positivo con marcadores T (UCHL-1 y CD3). Con todo ello se diagnosticó micosis fungoide folicular.

\section{DISCUSIÓN}

La micosis fungoide se considera un linfoma indolente originado de linfocitos CD4+ recirculantes con intensa afinidad cutánea, especialmente por epidermis. Predomina en edad adulta. La clínica comienza por la aparición de lesiones maculares inflamatorias, eritematosas y pruriginosas, difíciles de diferenciar de un eczema. En este caso, el diagnóstico se dificultaba por la presentación exclusivamente palpebral.

El diagnóstico de micosis fungoide en las primeras fases se basa en una buena correlación clínicopatológica. La inmunohistoquímica y la presencia de monoclonalidad en el reordenamiento genético suponen pruebas de gran ayuda (4).

No existe ningún tratamiento definitivo o curativo, existiendo diversas aproximaciones terapéuticas, así que se elige en cada paciente la más adecuada según el tipo y localización de las lesiones, extensión, estadío del linfoma (4). En nuestro caso, dificulta el tratamiento la localización lesional, impidiendo la utilización de corticoides tópicos de forma mantenida, quimioterápicos tópicos ni fototerapia. El uso de tratamientos sistémicos se reserva para las fases más avanzadas. La radioterapia local también puede usarse (4).

Suchin et al publicaron el tratamiento exitoso con Imiquimod $0,5 \%$ en crema en dos pacientes con micosis fungoide en placa (5). Imiquimod (Alda$\mathrm{ra}^{\circledR}, 3 \mathrm{M}$ España S. A., Madrid, España) es un inmunomodulador que estimula las citoquinas TH1, incluyendo los interferones alfa y gamma y la interleucina 12. También aumenta la actividad de las células NK y la expresión del Factor de Necrosis Tumoral $\alpha$ (5). En nuestro paciente, Imiquimod logró reducir las lesiones, eliminando la inflamación, aunque persistieron algunos quistes de millium, desde el punto de vista clínico, y un infiltrado inflamatorio perifolicular desde el punto de vista histológico.

En conclusión, presentamos un caso de micosis fungoide folicular exclusivamente palpebral con buena respuesta al tratamiento con Imiquimod. Dada la importancia clínica y la posibilidad de leucemización de estas enfermedades debemos resaltar la importancia de vigilar las lesiones palpebrales crónicas e incluir en su diagnóstico diferencial la micosis fungoide. Así realizaremos una correcta correlación clínico-patológica para diferenciarla de patologías más frecuentes y banales en esta localización como los eczemas.

\section{BIBLIOGRAFÍA}

1. Montserrat Costa E, Díaz-Mediavilla J, Moraleda Jiménez JM, Campo Guerri E, Bosch Albareda F, López-Guillermo A, et al. Enfermedades ganglionares. In :FarrerasRozman. Compendio de Medicina Interna. Madrid: Elsevier España S.A.; 2004; II: 1728-1757.

2. Durand L, Magnard G, Trepsat C. Palpebral localization of mycosis fungoides. Therapeutic attitude. Bull Soc Ophtalmol Fr 1971; 71: 723-724.

3. Wong SS, Goh CL. Milia en plaque. Clin Exp Dermatol 1999; 24: 81: 183-185.

4. Gallardo F, Pujol RM. Diagnóstico y tratamiento de los linfomas cutáneos de células T primarios. Actas Dermosifiliogr 2004; 95: 473-490.

5. Suchin KR, Junkins-Hopkins JM, Rook AH. Treatment of stage IA cutaneous T-Cell lymphoma with topical application of the immune response modifier imiquimod. Arch Dermatol 2002; 138: 1137-1139.: 